SHS Web of Conferences 23, 02007 (2016)

DOI: $10.1051 /$ shsconf/ 20162302007

(C) Owned by the authors, published by EDP Sciences, 2016

\title{
A PROPOSED FOR ASSESSING HOTEL E-READINESS FOR TOURISM IN SOUTHERN THAILAND
}

\author{
Sirot Piman ${ }^{1}$ and Wanchalerm Poldee \\ Business Computer Department, Faculty of Management Sciences \\ Suratthani Rajabath University, Thailand 84100 \\ E-mail : sru.sirot@hotmail.com,wanchalerm.it@gmail.com
}

\begin{abstract}
This article only focuses on an overview of the Hotel E-readiness model and model design for tourism in Southern Thailand. "The convergence of information technology (IT) and communications technology (CT)" will be an important part of these technological innovations. The global economy has been turbulent during the last several years, and governments and enterprises are doing everything possible to inject momentum and effectuate sustainable growth. All member countries of Association of Southeast Asian Nations (ASEAN), aims to be ASEAN Economic Community (AEC) by December 2015, have come to realize that an integrated ICT technology will enhance the competitiveness and creativity of their economies and fuel the sustainable growth of the global economy. The role that information and communication technologies (ICTs) can play to support economic growth, especially on tourism, has never drawn so much attention and research. According to Networked Readiness Index (NRI), Thailand has made improvement in NRI, edging up from 77th to 74th place in 2013 and from 74th to 67th place to the latest measurement released by the World Economic Forum in 2014 and ranked 3 out of 10 countries of ASEAN members. Although we still face serious challenges the impact of ICTs on tourism has become more far reaching as its transformational effects spread to several sectors of the economy and society via innovations. On this research we focus on only the hotels division in Southern of Thailand due to tourism's economic on this area benefits very high income from oversea and ASEAN. We give an overview of the Hotel E-readiness Model that impact to tourism economic with computer networking infrastructures and communication technologies in Southern of Thailand. Our model is described on four majors - business environment, network readiness, network usage and network impacts. It aims to explore the problems and obstacles for improvement on computer networking infrastructure and communication technologies on tourism economic in southern of Thailand. Finally of this research to find out the ways and give the suggestions to improve and develop our computer networking infrastructures and communication technologies for tourism economic in southern of Thailand.
\end{abstract}

Key words : Tourism Communication, ASEAN Economy, Computer Network Infrastructures, ICTs

\section{INTRODUCTION}

The use of technology has become an imperative need to compete with other enterprises. It is worth to mention that there are other elements to consider in order to become a competitive enterprise, but inside them is the technology that it is essential to keep in contact with the globalized society nowadays. When an enterprise plans clearly the objectives 
of the technology, acquires it and has the trained personal to used it, it will get benefits and results that will reflect according to the established objectives. This is called -E-readiness-. The creation of a model that allows evaluating what is the amount of utilization in the use of technology at hotels, how it is used, what was the main objective of its acquisition and in which way the hotel are reaching the objectives by using ICTs. All the information obtained by the application of the model will help to make recommendations of improvement to owners and employees of accommodation enterprises that are willing to be competitive ( Schmidt C. \& Sugias E.,2011).

The 10-member Association of Southeast Asian Nations, ASEAN, is arguably the most durable and successful regional grouping in the developing world. Established in 1967, it has contributed greatly to regional harmony and prosperity. ASEAN is characterized by great internal diversity, generally high economic growth, and a reluctance to establish a strong supranational structure. Beginning in 1976-with its five original members-ASEAN began to move toward economic cooperation and integration, initially with a focus on merchandise trade. In the 1990s, it added focus on services, investment, and labor (Hal H. \& Jayant M., 2010). All member countries of Association of Southeast Asian Nations (ASEAN), aims to be ASEAN Economic Community (AEC) by December 2015, have come to realize that an integrated information and communication technologies (ICTs) will enhance the competitiveness and creativity of their economies and fuel the sustainable growth of the global economy. Base on Networked Readiness Index (NRI), Thailand has made improvement in NRI, edging up from 77th to 74th place in 2013 (Benat B. O., Soumitra D. \& Bruno L., 2013) and from 74th to 67th place to the latest measurement released by the World Economic Forum in 2014 and ranked 3 out of 10 countries of ASEAN members, in comparison as shown in table 1 .

Table 1 Networked Readiness Index (NRI) compare in ASEAN, year 2013

\begin{tabular}{|l|c|c|}
\hline \multicolumn{1}{|c|}{ County } & World ranking & ASEAN ranking \\
\hline Singapore & 2 & 1 \\
\hline Malaysia & 29 & 2 \\
\hline Thailand & 77 & 3 \\
\hline Indonesia & 80 & 4 \\
\hline Vietnam & 86 & 5 \\
\hline Loas & Out of rank & 6 \\
\hline Indonesia & Out of rank & 6 \\
\hline
\end{tabular}

Although we still face serious challenges the impact of ICT on tourism has become more far reaching as its transformational effects spread to several sectors of the economy and society via innovations. The hotels division in Southern of Thailand, include of 14 provinces, benefits very high income from oversea and ASEAN.

However, on this article we provide only an overview of the Hotel E-readiness Model that impact to tourism economic with computer networking infrastructures and communication technologies in Southern of Thailand. Our model is described in four majors business environment, network readiness, network usage and network impacts. Finally, we aim to use this model in the future to explore the problems and the obstacles for improvement on computer networking infrastructure and communication technologies on tourism economic in southern of Thailand.

\section{LITERATURE REVIEW}


E-readiness (electronic readiness) is a measure of the degree to which a country, nation or economy, willing or prepared to obtain benefits which arise from information and communication technologies (ITCs). This measure is often used to gauge how ready a country is to partake in electronic activities such as e-commerce and e-government countries. It most cases, e-readiness is presented in terms of indices, where countries are rated in various areas (Danish D., 2006). The results are tabulated and can then be used to make comparisons both between countries in the form of ranking, as well as longitudinal studies within. A vast number of e-readiness ranking will be formulated through research. Each ranking is often the product of difference methodologies, and divergent definitions of ereadiness. Lastly, the findings of the various studies are not consistent with each other.

However, there are some numerous limitations of e-readiness measures. This is largely due to the face that these indices are often regarded as overly simplistic solutions to extremely complex problems. Some attempt to overcome these problems by putting forward newer, refined, frameworks (Maugis e. a.,2005; Bui e. a.,2003), while others questions the validity of such projects, and the usefulness of their findings (bridge.org, 2005). This research provides only the model of e-readiness in the hotel divisions that will be developed become a tool with be used for final research results.

\section{PROPOSED MODEL}

We designed the model, is called "Hotel E-readiness Model", that become our research tool. Our model has been applied form two main models. Firstly, we have been designed a model to focus on the hotel business environment major that will be used for describing with the hotel indicators as shown in figure 1 .

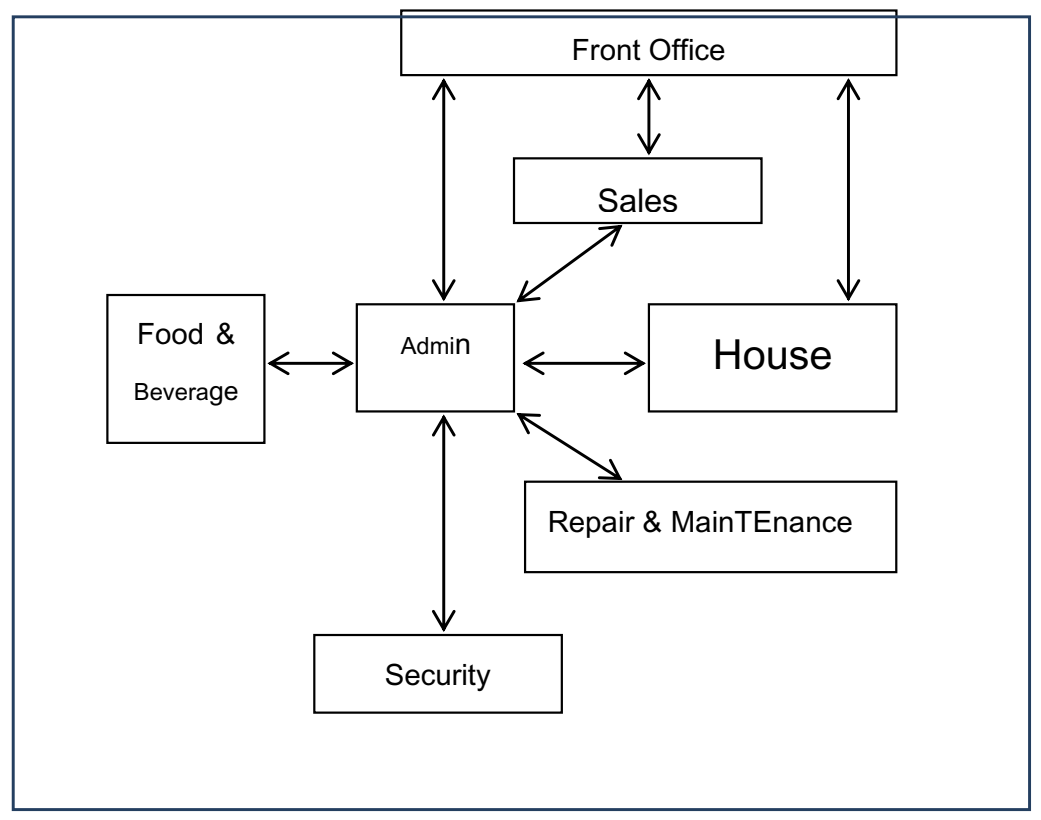

Figure 1 the hotel business environment 
Combine with the second model that we use to study an E-readiness model of the network readiness index (Benat B. O., Soumitra D. \& Bruno L. ,2013). This model will be used in detail of four important majors consist of network environment, network readiness, network usage and network impacts as shown in figure 2.

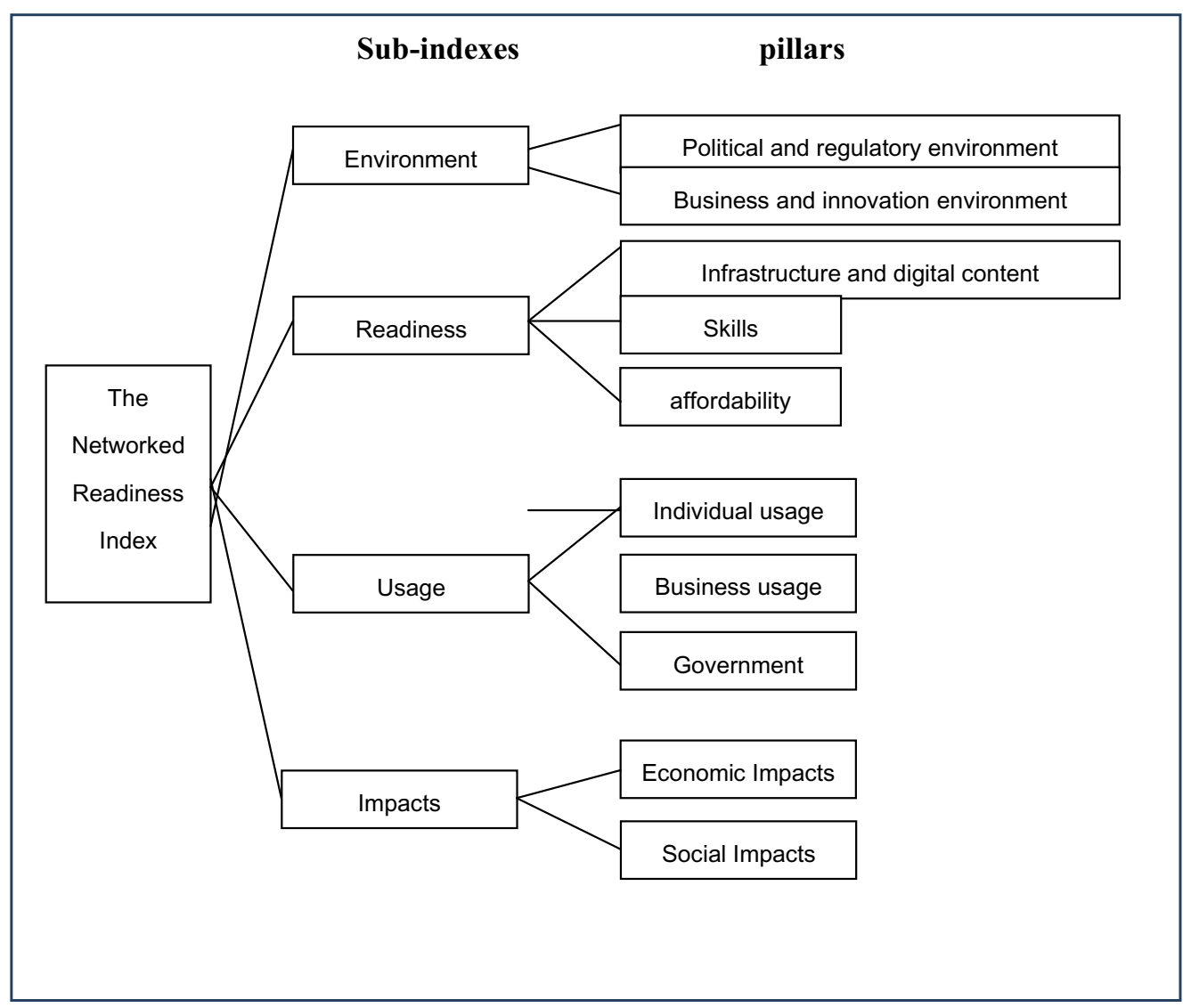

Figure 2 the networked readiness index model

The Hotel E-readiness model is composed of indicators for the four main ICTs factors - environment, readiness, usage and impacts- where these four factors contain a total of 11 ICTs sub-factors.

We aims to use this model to study the impact of computer networking infrastructure and communication technologies on tourism economic, find out the problems and obstacles for improvement on ICTs and will give the suggestions to improve and develop our computer networking infrastructures and communication technologies for tourism economic in southern of Thailand. 


\section{DATA COLLECTION AND SAMPLING GROUP}

In complete research, the model will be suitable for three main sampling groups consist of Hotel, Tourist and gateway host terminal, as shown in figure 3, to fulfill completely for those four majors research details.

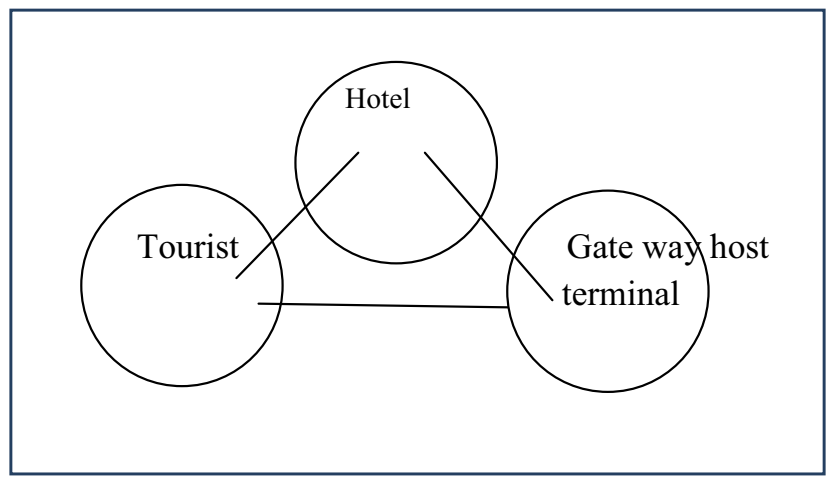

Figure 3 tree main dimensions of sampling group

For hotels, the research targets are 3 stars up of hotels in 14 provinces of southern Thailand to focus in deep on infrastructures, ICTs readiness, customer usage and economic impacts of each hotel. The selected hotels must have their own ICTs departments and ICTs system (Pornchai C. \& Bundid K., 2011). However, in booming area, YaLa, Patthani and Narathiwat province. We decide to collect data only Phattani province to be the sample that stand for all 3 provinces. The second sampling group is tourists, we focus on the satisfaction of hotel's ICTs. Lastly, is a sampling group of gateway host terminal that will be studied on political and government policies. We plan to interview individual face to face with specialist in ICTs technician who handle the ICTs policies in Thailand.

\section{CONCLUSION AND FUTURE WORK}

On this paper, we only give an overview of the Hotel E-readiness Model that impact to tourism economic with computer networking infrastructures and communication technologies in Southern of Thailand. We explain to how to design and develop the model to mapping with research data that we are interesting on four majors - business environment, network readiness, network usage and network impacts. For next future work, we will use this model to develop out research tool and going to the next step of our research,We aim to explore the problems and obstacles for improvement on computer networking infrastructure and communication technologies on tourism economic in southern of Thailand. Finally of this research to find out the ways and give the suggestions to improve and develop our computer networking infrastructures and communication technologies for tourism economic in southern of Thailand. 


\section{REFERENCES}

Benat B. O., Soumitra D. \& Bruno L. (2013). The Global Information Technology Report, Growth and Jobs in a Hyperconnected World p. 271.

Bridges.org (2005). eReady For What? E-Readiness in Developing Countries : Current Status and Prospects toward the Millennium Development Goals. http://www.infodev.org/files/2049_file_InfoDev_E_Rdnss_Rpt_rev11May05.pdf.

Danish D. (2006). E-readiness for Developing Countries : Moving the focus from the environment to the users. EJISDC(2006) conference 27(6) , 1-14.

Hal H., \& Jayant M. (2010). ASEAN Economic Integration: Features, Fulfillments, Failures and the Future, p. 1.

Maugis V.,Choucri N., Madnick S., Siegel M., Gillett S., Haghseta F., Zhu \& Best M. (2003). Global E-Readiness-for WHAT?. E-Business :A Research and Education Initiative at the MIT Sloan School of Management, paper 177.

Maugis V.,Choucri N., Madnick S., Siegel M., Gillett S., Haghseta F., Zhu \& Best M. (2005). Global E-Readiness-for WHAT? Readiness for e-Banking, Information Technology for Development, 11,4,313-342.

Pongchai C. \& Bundid K., ICT readiness assessment model for public and private organizations in developing country, p.100.

Schmidt C. \& Sugias E.(2011). Proposal of a model to assess the level of E-readiness in hotel companies. Implementation in the State of Colima, P. 1. 